Article

\title{
Enhancing Performance of Participatory Water Institutions in the Eastern Indo-Gangetic Plains: What Can We Learn from New Institutional Economics and Governance Theories?
}

\author{
Vasant P. Gandhi * and Nicky Johnson $\mathbb{D}$ \\ Indian Institute of Management Ahmedabad, Ahmedabad 380015, India; nickyj@iima.ac.in \\ * Correspondence: gandhi@iima.ac.in
}

Received: 15 November 2019; Accepted: 18 December 2019; Published: 23 December 2019

\begin{abstract}
The paper examines the performance of participatory water institutions in India's Eastern Indo-Gangetic plains region using new institutional economics and management governance fundamentals. Water institutions are of great importance for water resource management in India's Eastern Indo-Gangetic plains since the region has relatively abundant water but lags behind significantly in economic development and growth with a high incidence of poverty. Engineering solutions to water management have been implemented but have not given good results principally because of weak institutional development and design in the region. Effective and efficient participatory water institutions are urgently needed. The research uses concepts from new institutional economics and management governance theory to build a conceptual framework for explaining the performance of participatory water institutions. The framework identifies eight institutional rationalities: technical, environmental, economic, social, political organizational, financial and government; as well as five institutional features: clear objectives, good interaction, adaptiveness, right scale, and compliance, as linked to performance. Based on this, a survey instrument was developed and a survey conducted obtaining responses from more than 500 households across 51 such institutions in the eastern Indo-Gangetic plains states of Assam and Bihar. The data were analyzed through statistical and econometric techniques including Ordered-Probit. The results support the relevance of the concepts in explaining performance of water institutions, and a number of drivers of performance were identified through Ordered-Probit, particularly, four rationalities-technical, economic, social and organizational, (with coefficients $(0.4622,0.3803,0.4303,0.2457)$ and three institutional features—good interaction, adaptiveness and appropriate scale (with coefficients 0.4242 , $0.2703,0.6756$ ) (based on a 5-point Likert scale), as playing a positive and significant role in enhancing performance. The results provide a number of useful insights which can help guide interventions and policy towards better design and development of the water institutions, and help improve water resource management and livelihoods in the region.
\end{abstract}

Keywords: water; participatory irrigation management; new institutional economics; India

\section{Introduction}

The paper examines the nature and performance of participatory water institutions in the eastern Indo-Gangetic plains using fundamentals from new institutional economics and management governance theory. Although the physical development of irrigation has made considerable progress in India, the efficient distribution and management of water for agriculture is posing many difficulties $[1,2]$. Engineering solutions are by themselves unable to provide the answer since the problems are substantially rooted in poor institutional development and design [1,3-7]. The consequences of weak 
institutions are frequently poor efficiency in water use, low crop productivity, environmental cost, inequity, disputes and substantial under-utilization of the potential. In some areas, though, better local institutional development and initiatives can be seen and show a process of learning with lessons for better institutional arrangements for managing the water.

Eastern India and the Eastern Indo-Gangetic plain regions typically show low per-capita income levels, high incidence of poverty, and poor development, presenting a significant challenge for national development policy. Paradoxically, compared to many other parts of the country, the region generally has better natural resources for agriculture including relatively abundant water supply from Himalayan rivers. If effectively managed, this could support a strong agriculture sector and good economic growth. Far more water scarce west, north and south regions of India are doing better in harnessing their limited water resources for growth and development. The consequence of poor management of water in the east is seen frequently in excessive water in some months/years and some areas-including devastation of crops and assets by floods, but substantial water scarcity in other months and areas especially in times of drought [8]. This seriously affects the agricultural and overall development in the region.

\section{Background and Justification}

Eastern India consists of the east and the northeast; the east includes the states of Bihar, West Bengal, Jharkhand and Orissa, and the northeast includes the large states of Assam, Meghalaya, and Arunachal Pradesh, and small states of Manipur, Mizoram, Nagaland, Sikkim, and Tripura. Eastern India has a huge diversity of people including numerous tribes, and a large diversity of plant and animal life. It is rich in natural resources, including water, forests and minerals, and could be among the wealthy regions of the country [9]. However, it lags in development, with low per capita incomes and income growth rates, high incidence of poverty, more incidence of violence, and substantial natural resource degradation. The agriculture sector which constitutes a large share of the region's economy also lags behind, and the region lags in the acceleration of economic growth seen in other parts of India. Figure 1 shows the study areas in Eastern India.

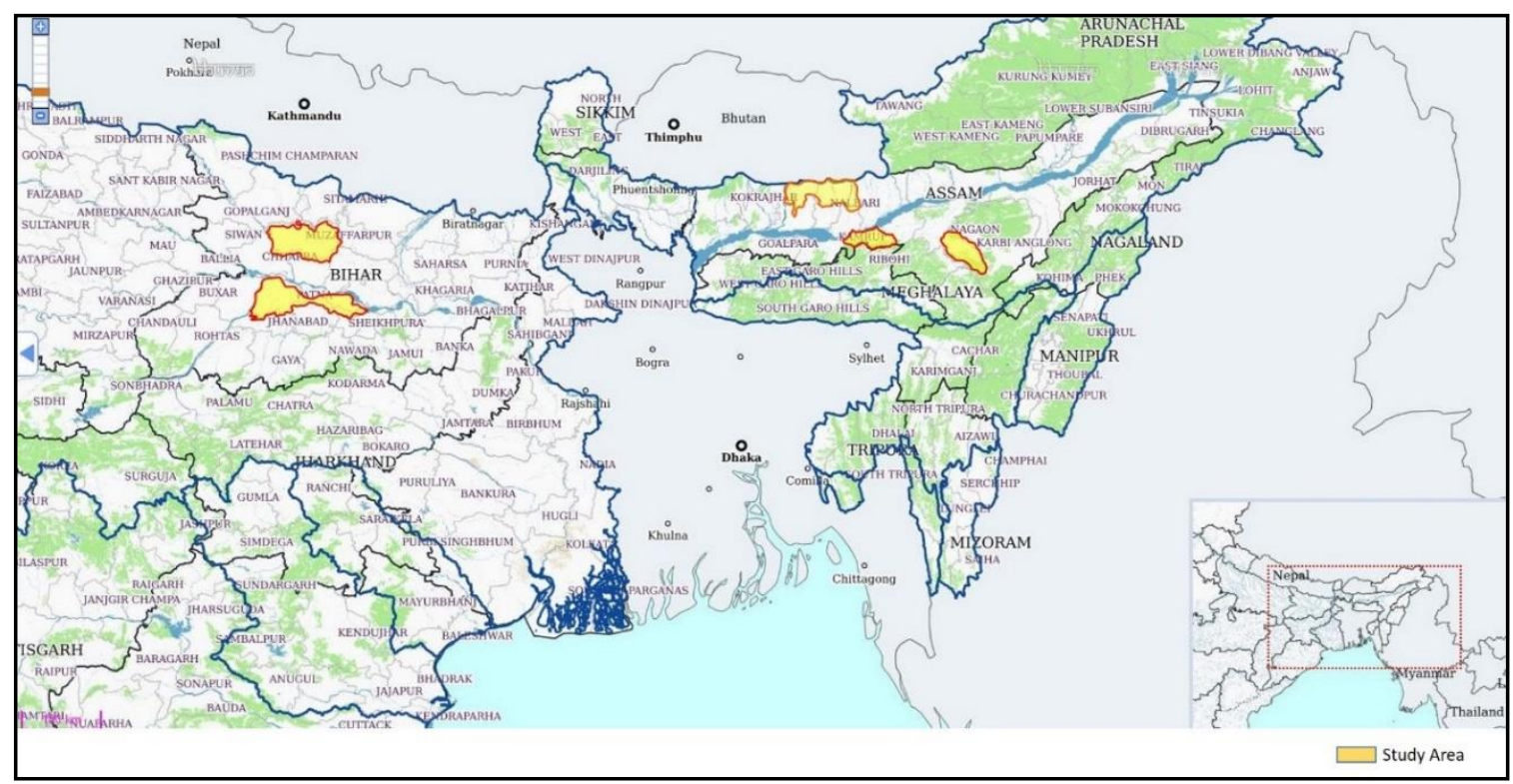

Figure 1. Location of study areas in Eastern India. Sources: Bhuvan: ISRO/NRSC, 2019 and Google Earth, 2019.

As mentioned, Eastern India has relatively abundant water resources-Figure 2, which shows the different river basin flows in India, indicates that the Ganga and Brahmaputra basins in eastern India 
account for the lion's share of water flows in India. The Brahmaputra and Barak rivers in the northeast account for one-third of India's runoff flows [10]. The basins also contain substantial seasonally flooded wetlands that sustain a huge range of biodiversity. The abundant surface flows also lead to substantial distress and costs through frequent floods, erosion and siltation, though the region also has substantial underutilized groundwater resource.

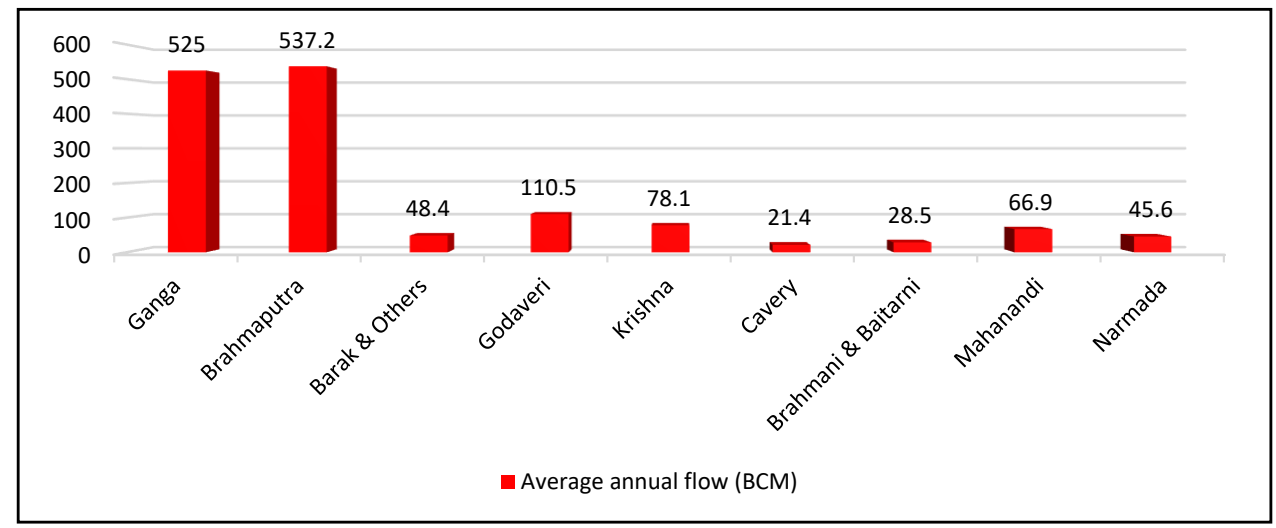

Figure 2. River basin flows in India (2015). Source: Water and Related Statistics (2015), Central Water Commission BCM: Billion Cubic Meter.

Table 1 outlines the irrigation potential in eastern India by state, and indicates that this is substantial at more than 33 million hectares [10]. Bihar has the largest share, followed by Orissa, West Bengal and then Assam. The central government has been taking a large role in managing water resource in eastern India, partly due to weak state capacity. Despite generous central government transfers, the region shows large fiscal deficits, poor service quality, and poor infrastructure provision [11]. An important reason is that the institutional arrangements are complex, incomplete and over-focus on top-down accountability rather than desired functional outcomes. The World Bank (2007) [11] finds significant weaknesses in the institutional setup governing the northeast, and indicates that without institutional arrangements which can bring active cooperation of the stakeholders, neither better management nor development can take place. The World Bank finds that in the water-related sector in the northeast the links into the community based institutional arrangements are limited or do not exist, whether it is for water resource management or watershed development.

Table 1. Eastern India state-wise irrigation potential ('000 hectares).

\begin{tabular}{|c|c|c|c|c|c|}
\hline \multirow{2}{*}{ State/U.T. } & \multirow{2}{*}{$\begin{array}{l}\text { Major \& Medium } \\
\text { Irrigation Projects } \\
\text { Surface Water }\end{array}$} & \multicolumn{3}{|c|}{ Minor Irrigation } & \multirow{2}{*}{$\begin{array}{c}\text { Total (Major, } \\
\text { Medium \& Minor) }\end{array}$} \\
\hline & & Surface Water & Ground Water & Total & \\
\hline $\begin{array}{c}\text { Arunachal } \\
\text { Pradesh }\end{array}$ & 0 & 150 & 18 & 168 & 168 \\
\hline Assam & 970 & 1000 & 900 & 1900 & 2870 \\
\hline Bihar & 5224 & 1544 & 4120 & 5664 & 10,888 \\
\hline Jharkhand & 1276 & 354 & 830 & 1184 & 2460 \\
\hline Manipur & 135 & 100 & 369 & 469 & 604 \\
\hline Meghalaya & 20 & 85 & 63 & 148 & 168 \\
\hline Mizoram & 0 & 65 & 5 & 70 & 70 \\
\hline Nagaland & 10 & 70 & 5 & 75 & 85 \\
\hline Orissa & 3600 & 1000 & 4203 & 5203 & 8803 \\
\hline Sikkim & 20 & 50 & 0 & 50 & 70 \\
\hline Tripura & 100 & 100 & 81 & 181 & 281 \\
\hline West Bengal & 2300 & 1300 & 3318 & 4618 & 6918 \\
\hline Total & 13,655 & 5818 & 13,912 & 19,730 & 33,385 \\
\hline
\end{tabular}

Local stakeholders have been frequently questioning the current institutional arrangements and the limited benefits to the local populations. A major feature of this is that the efforts of government to date have been overly-directed only towards technical design and structures. The United Nations Children's Fund (UNICEF, 2013) [12] finds that India's water sector is dominated by engineers but the 
projects almost always have huge social, political and environmental connections The complexity of existing water resource management requires an interdisciplinary approach and the present engineering education provides no exposure to social sciences. The World Bank (2007) [11] finds that in the context of both water resource and forest management, without active cooperation of the stakeholders no effective development or management can occur. The current engineering-dominated departments focused on technical outcomes need reorientation and reform to include social and environmental aspects. The World Bank (2007) [11] recommends a resource-led strategy for broad-based development in eastern India, and indicates that this can be achieved only through an institutional environment that has been appropriately reformed and strengthened. The World Bank [11] indicates that the most important priority to deal with the vicious cycle of poor development that the region is caught in, is to address the institutional setup and reshape and create an appropriate participatory institutional framework to enable a more effective regional development path.

\section{Concepts: New Institutional Economics, Institutional Design and Governance}

Given the critical need to reform the water institutions in eastern India, it is essential first to understand what are institutions, and what is their linkage to performance. Institutions are conceptually defined as humanly devised constraints that structure human interaction [13]. Further to the factors of capital, labor and technology, institutions have been now recognized as a major factor in determining performance, based on new institutional economics. Institutions include "macro" institutions-the formal "rules of the game": such as the constitution, laws and property rights, and informal rules such as traditions, norms and codes of conduct; and include "micro" institutions, such as institutions of governance including market or non-market modes of managing transactions and seeing activities through [14-16].

The need and rationale for the presence of institutions is found primarily in the existence of transaction costs $[17,18]$. But transaction costs are usually ignored given the large focus on hard transformation costs (such as on capital, labor and technology), and when transaction costs become large, they destroy performance. Good institutions help to lower the transaction costs. According to North [17] the major challenge is to evolve institutions which: (1) Minimize transaction costs (2) Create incentives that favour co-operative solution, in which cumulative experiences and collective learning are best utilised.

In practice, transaction costs are generally difficult to accurately identify and measure. In this context, based on an understanding of the aforementioned concepts of new institutional economics, and the recent applied literature on water management institutions of Pagan, Ostrom, Crase, Gandhi and others [1,3,4,19-22], have identified a set of five observable proxy features/variables in institutions that closely relate to transaction costs as well as the new institutional economics fundamentals described above. These can be stated as:

1. Clear objectives: clear objectives and clarity of purpose in the institution and their acceptance by all stakeholders leads to better congruence, less conflict, and lower transaction costs.

2. Good interaction: good interaction (including meetings) help to bring the formal and informal (rules) together (internal and external), thereby lowering transaction costs, and promoting cooperative solutions-using cumulative experiences and collective learning.

3. Adaptiveness: adaptiveness as opposed to rigidity, reduces transaction costs and improves inclusion and sustainability in face of changing internal and external environment.

4. Appropriate scale: appropriate scale in size, scope and decision domain. Institutions that are too large have high transaction costs, and if too small, are unable to lower transaction and other costs.

5. Compliance: institutions are made up of rules. Without stakeholder compliance to the rules of the institution, they cannot lower transaction costs and create impact. 
Relevant concepts have also been derived also from management concepts and theory of organizational design and governance [23-25], identified in [26,27]. These indicate that sound governance of institutions/organizations needs addressing of at least three important rationalities:

1. Technical rationality: efficient conversion of inputs to outputs: Good institutions must deliver technical rationality leading to high technical efficiency. Requirements include sound technology and other determinants of high productive efficiency such as expertise, design, waste recovery and automated controls.

2. Organizational rationality: division of labor, specialization, and effective coordination. Good institutions must deliver organizational rationality. This includes sound division of labor/responsibilities, and specialization in functions, and effective coordination across them to best achieve overall goals.

3. Political rationality: sense of fairness and justice. Good larger institutions must provide political rationality. Given human involvement/interdependence in institutions, concerns of fairness and justice must be addressed for sustainable performance.

\section{Expansion of the Framework}

In order to examine the applicability of this conceptual framework at the ground level, 16 case studies of water user institutions were done in the states of Gujarat, Maharashtra and Andhra Pradesh in India under an Australian Centre for International Agricultural Research (ACIAR)-supported project in 2004. Later, for institutions in watershed management, six in-depth case studies were done under an ACIAR project in 2009 in Andhra Pradesh state. Again, for water user associations in eastern India, six in-depth case studies were done in 2017 in the states of Assam and Bihar. The names/locations of the eastern India Water Users Association (Central Level Committee, CLC) case studies are listed in Table 2.

Table 2. Case studies of water user associations in the Eastern Indo-Gangetic plains.

\begin{tabular}{cccc}
\hline SI.no. & $\begin{array}{c}\text { Water User Association } \\
\text { Central Level Committee (CLC) }\end{array}$ & State & Type \\
\hline 1 & Maloibari & Assam & River Lift \\
2 & Sukhajani & Assam & Canal \\
3 & Khairani & Assam & River Diversion \\
4 & Paligunj & Bihar & Canal \\
5 & Jetwalia & Bihar & Canal \\
6 & R P Channel 3 & Bihar & Canal \\
\hline
\end{tabular}

The case studies found the concepts to be quite relevant and applicable in understanding water institution performance in India, but based on the observations of the watershed management case studies in Andhra Pradesh [28], and the case studies in eastern India, it was found that whereas the concepts based on new institutional economics were adequate, it was necessary to considerably expand the list of rationalities identified through the management governance theory. The expanded list found important and relevant for these water institutions is given below:

- Technical rationality

- Environmental rationality

- Economic rationality

- Social rationality

- Political rationality

- Organizational rationality

- Financial rationality

- Government rationality 
The meaning or concept of these rationalities in the context of water institutions and agriculture in India is described below:

\section{Technical Rationality}

Technical rationality addresses the most efficient conversion of inputs to outputs. This requires right inputs/technology and operational methods leading to high productive efficiency. It usually requires input from technically trained experts. In the context of water resource management, the rationality includes sound location of structures, planning, good inputs, technology, structures/equipment, specifications and construction, as well as repair and maintenance.

\section{Environmental Rationality}

This takes into consideration the environment and its conservation. The natural resources are often fragile/scarce/poor, especially water and land. The rationality requires the care and conservation of water, land and natural vegetation, good drainage, and avoiding over-exploitation, so that performance/outcomes are durable and sustainable.

\section{Economic Rationality}

This deals with the considerations of benefits, costs, returns and incomes of the activities and effective use of scarce resources. It involves selection of right activities from the point of view of markets, demand, prices, profitability and returns to investment. It includes infrastructure and marketing arrangements. This is very important for good impact on incomes, livelihoods and development.

\section{Social Rationality}

This takes into consideration the social or people setting. In the rural areas of India, farm sizes are small. and huge numbers of people are dependent on the land for livelihoods, often belonging to many traditional social groups. This may include various castes, tribes, religions, professions, landholding-sizes, men, women, rich and poor. The rationality calls for their involvement/cooperation/inclusion with equitable distribution of costs and benefits, for better and sustainable outcomes.

\section{Political Rationality}

Political rationality deals with various leaders, powers, individuals, and interest groups that historically exist, and their perception of fairness and justice. This may require their representation and participation from early stages, and the balancing of needs and concerns. Otherwise, conflicts and non-acceptance may undermine the activity or institution.

\section{Organizational Rationality}

Organizational rationality deals with the good organization and coordination of activities. Division of labor and specialization leads to separate activities and responsibilities. Effective coordination across these is needed for good overall performance. This may require managerial and leadership skills and knowledge, as well as organizing activity groups, committees and meetings. The ability to deal with the government/external bodies and their procedures is also required.

\section{Financial Rationality}

This calls for discipline and care in the handling of money/financial resources. Substantial financial resources are often provided by the government or raised from members or other agencies. To see that they are effectively used for the intended purpose and not misused or lost, good accounting systems and procedures are needed. Otherwise, losses, conflicts and government sanctions may arise.

\section{Government Rationality}


Government often plays a major role in bringing change and development. Government rationality deals with the kind, quantum, design and speed of government support. It includes laws, rules, appropriate design of government schemes, its guidelines, budgets and procedures. It also includes the active involvement and commitment of the government officials including their knowledge, skills and help in mobilizing, guiding and training the participants.

The aforementioned institutional features and rationalities are combined into a conceptual framework for application in this study. The framework is outlined in the Figure 3 below.

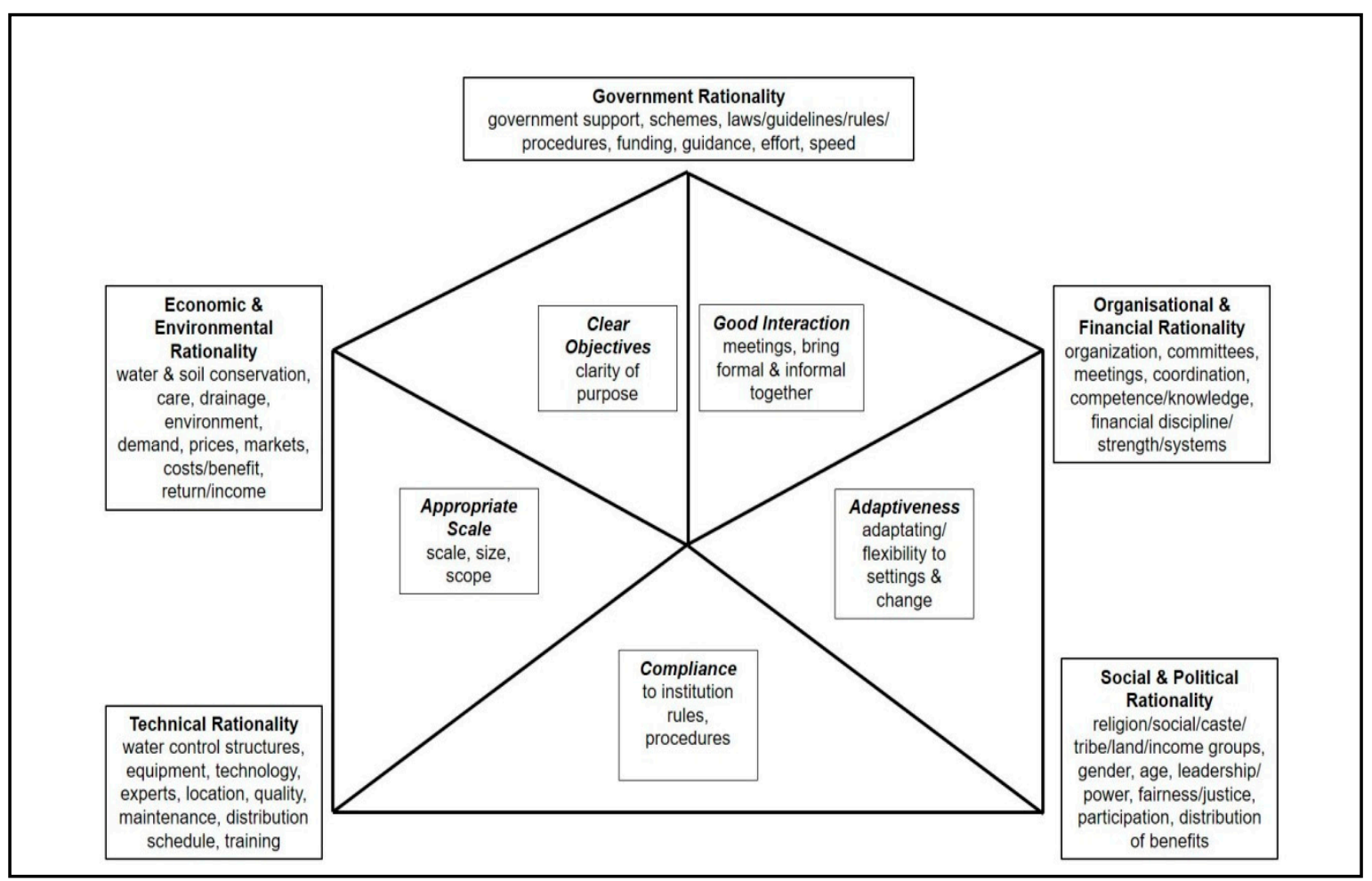

Figure 3. Conceptual Framework.

\section{Survey and Data}

Based on the conceptual framework and the understanding from the case studies, detailed survey instruments were designed to collect the responses from a sample of respondents on the required aspects and features needed for the research. The types of survey questionnaires that were developed included: Farmer-Institutional Questionnaire, Compliance Questionnaire, Gender/Women Questionnaire, and Discrete Choice Experiment (DCE) Questionnaire.

The total number of questionnaires canvassed in the survey was 1132 . This paper principally uses data from the Farmer-Institutional survey in which data was collected in the eastern India states of Assam and Bihar during 2018 from sample beneficiary farmer households across a number of water user associations, through sampling. The sampling is across farm sizes: marginal, small, medium, large. All farm sizes were not present in the villages under the covered CLC areas. 510 farm households were covered across 51 water-user associations (WUA) (Village Level Committees, VLCs), see Table 3. Data from the other surveys is examined in other papers. 
Table 3. Survey sample coverage.

\begin{tabular}{ccc}
\hline State & Survey & Sample Size \\
\hline Assam & Farmer-Institutional survey & 252 \\
Bihar & Farmer-Institutional survey & 258 \\
Total & Farmer-Institutional survey & 510 \\
& Total No. of Water-User & 51 \\
& Associations & \\
\hline
\end{tabular}

\section{Sample Profile and Features}

The farmer sample landholding profile is outlined in the Figure 4 below. The figure indicates that marginal farmers $(<1$ hectare) constitute the largest share in the sample at 52 percent, followed by small farmers (1-2 hectares) at 30 percent, medium farmers (2-10 hectares) at 18 percent, and large farmers ( $>10$ hectares) none. Secondary data of Assam and Bihar states shows that marginal farmers constitute a huge proportion of 87.9 percent, small farmers 7.5 percent, medium farmers 4.5 percent, and large farmers 0.04 percent of the farm households [29]. This indicates that the survey sample has a lower than proportionate share of marginal farmers, and larger than proportionate share of small and medium farmers.

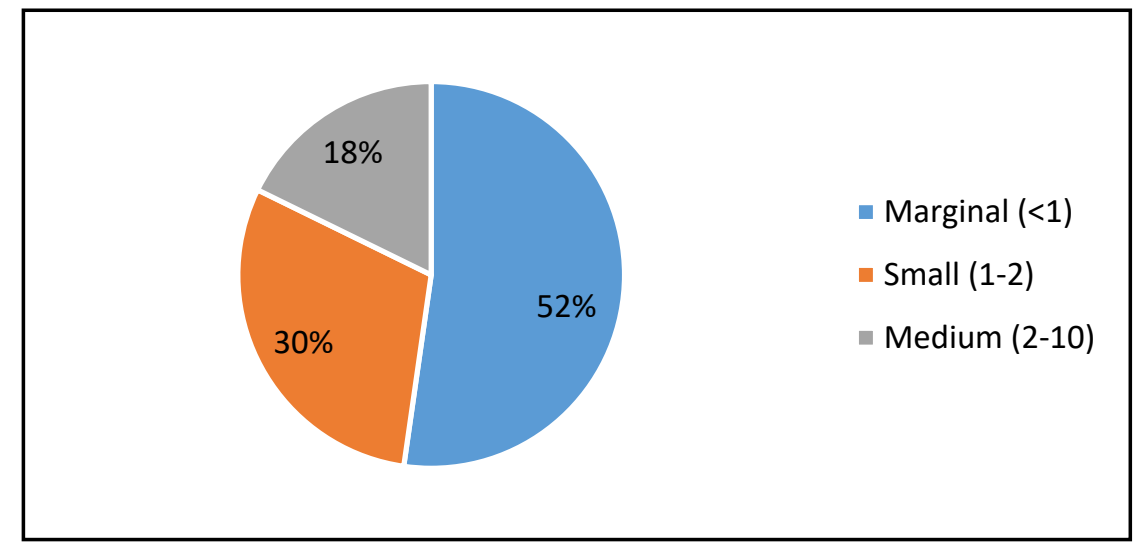

Figure 4. Sample farmer landholding.

Table 4 gives the average landholding profile of the sample: owned, leased-in, leased-out operated, irrigated, and unirrigated. The table indicates that the average owned landholding owned is 1.22 hectares, and operated landholding is 1.32 hectares. Secondary data for Assam and Bihar shows average landholding to be 0.49 hectares [26]. This indicates the prevalence of very small landholdings, and that the average survey sample landholdings are larger, which is line with greater than proportionate sampling of small and medium farmers. The percentage area irrigated in the sample works out to 89 percent. The state figures indicate an average net irrigated area percentage of 40.7 percent [29]. This indicates that the survey households have more irrigation than the state average, and this is because the survey focuses on irrigation and water user association beneficiaries given its purpose.

Table 4. Landholding profile-mean (hectares).

\begin{tabular}{cccc}
\hline Landholding & Irrigated & Unirrigated & Total \\
\hline Owned & 1.08 & 0.14 & 1.22 \\
Leased in & 0.16 & 0.01 & 0.17 \\
Leased out & 0.05 & 0.01 & 0.06 \\
Total Operated & 1.18 & 0.14 & 1.32 \\
\hline
\end{tabular}


Table 5 shows the profile on some features of the water situation and institutional environment in the sample from the data. It indicates that the majority of farmers report facing water scarcity. This shows that despite the perception that there is water abundance in the east, a majority of farmers face water scarcity for agriculture-indicating that they need irrigation. Whereas about 20 percent of the sample farmers indicate that they are affected by floods, about 40 percent indicate that they are affected by drought, indicating a significant incidence of drought even in the water abundant setting. Despite the investment in irrigation and participatory irrigation management, about 60 percent indicate no improvement in water availability, but about 40 percent report improvement.

Table 5. Features of the water situation, water-user association (WUA) and institutional environment.

\begin{tabular}{|c|c|c|c|c|c|c|}
\hline \multirow[b]{2}{*}{ Features } & \multicolumn{5}{|c|}{ Percentage } & \multirow[b]{2}{*}{ Mean } \\
\hline & $\begin{array}{r}\text { Strongly } \\
\text { Agree (5) }\end{array}$ & Agree (4) & $\begin{array}{c}\text { Partly } \\
\text { Agree/Disagree (3) }\end{array}$ & Disagree (2) & $\begin{array}{c}\text { Strongly } \\
\text { Disagree (1) }\end{array}$ & \\
\hline 1. You face water scarcity on your farm & 23.1 & 45.5 & 6.3 & 22.2 & 2.9 & 3.6 \\
\hline 3. Your farm/village is affected by droughts & 3.3 & 26.1 & 13.9 & 37.3 & 19.4 & 2.6 \\
\hline 4. The water availability has improved over the years & 5.1 & 30.8 & 6.7 & 37.8 & 19.6 & 2.6 \\
\hline 5. The land/soils on your farm are good for cropping & 24.9 & 64.3 & 4.5 & 5.3 & 1.0 & 4.1 \\
\hline 8. The WUA has been formed by the government & 8.8 & 29.4 & 3.7 & 34.5 & 23.5 & 2.7 \\
\hline 9. The WUA is controlled \& managed by the government & 3.9 & 26.3 & 10.2 & 40.2 & 19.4 & 2.6 \\
\hline 10. The WUA is managed by the farmers & 26.1 & 42.2 & 5.5 & 19.0 & 7.3 & 3.6 \\
\hline
\end{tabular}

About 90 percent of the farmers indicate that their land/soils are good for cropping-showing the generally good fertility conditions in the eastern Indo-Gangetic plains. About 90 percent indicate that they use modern technology-showing that there is wide use of new agricultural technology. With respect to participatory irrigation management and WUAs, nearly 60 percent indicate that they are highly dependent on the WUAs-showing their great importance. With respect to the formation and running of the WUAs, about 70 percent indicate that the WUAs are managed by the farmers and about 60 percent disagree that they are formed and managed by the government. This indicates substantial involvement and participation of the farmers in the creation and running of the WUAs, as against a dominant role of the government though this may exist to some extent.

\section{Assessment of Rationalities}

In the survey questionnaire, questions were asked to the sample farmers regarding their assessment of the status of the WUAs on different rationalities mentioned above in the theory and framework. About 5 to 7 pertinent questions were designed and asked to assess the status on each rationality on a Likert scale of 5 to 1 , from strongly agree to strongly disagree. Similar questions were used earlier in a comparable context but different area by Gandhi, Crase and Roy [27] and were found to provide reasonable measures of the factors. They were adapted slightly to the given setting on the basis of the contextual information from six case studies carried out. Table 6 summarizes the results in terms of the agree response percentage (strongly agree plus agree) on each question, as well as the mean of the response-for technical, environmental, economic and social rationalities.

The results indicate that there is substantial variation in the responses. On technical rationality, the results indicate, that whereas most find the location and placement of structures to be sound, many indicate that the structures and equipment are not adequate, and that government expertise and training are not available adequately. Repair and maintenance are also indicated by many as inadequate. On environmental rationality, most find that there is not much problem of water logging and that care is taken of the environment. Lack of control of flooding and inadequate subsequent repair is a problem, and there is deterioration of the water/groundwater resource. On economic rationality it is found that farming activity and the environment lead to a strong demand for water, but crop diversification for improving the economic value is lacking, and the infrastructure for marketing/processing is inadequate. On social rationality, it is found that inclusion/concern for various social groups, small/marginal farmers, 
poor/weaker social groups and older people is present, and all have an opportunity to participate, but inclusion of women as well as youth is highly inadequate.

Table 7 reports on the assessment of political, organizational, financial and government rationalities. On political rationality, it finds that there is good prevalence of politically able leadership, consensus/less of conflict, good representation of older people, and ability to ensure fairness and justice. But representation of women and youth is low, and there is inadequate participation/representation of the various groups/leaders in the organization and committees of WUA. On organizational rationality it is found that the leadership and staff are knowledgeable and competent, but the meetings are not regular, and the ability to foster participation and deal with government is often inadequate. On financial rationality it is found that there are good arrangements for receiving, accounting for and disbursing funds, but the depositing with the government and receiving of government funds is inadequate, and the WUAs are often not financially sound. On government rationality, the government charges are thought to be reasonable, but on other aspects of government rationality, such as providing sufficient manpower and help, the level is inadequate.

Table 6. Assessment of rationalities-percent response.

\begin{tabular}{|c|c|c|}
\hline Rationalities & Agree $\%$ & Mean \\
\hline \multicolumn{3}{|l|}{ 1. Technical Rationality } \\
\hline 1. The location and placement of the irrigation structures/equipment is technically sound & 83.9 & 4.1 \\
\hline 3. The structures and equipment are adequate & 29.4 & 2.5 \\
\hline 4. The structures and equipment are regularly repaired and well maintained & 39.4 & 2.8 \\
\hline 6. The water release/distribution are technically well scheduled and managed & 45.5 & 2.9 \\
\hline 7. Technical training and guidance are available and provided to all involved & 22.5 & 2.3 \\
\hline \multicolumn{3}{|l|}{ 2. Environmental Rationality } \\
\hline $\begin{array}{l}\text { 1. The environmental care and problems are well addressed (including water conservation, soil conservation, } \\
\text { soil fertility, natural vegetation and life) }\end{array}$ & 52.5 & 3.1 \\
\hline 5. There is no deterioration in the groundwater table/water resources due to irrigation activities & 46.9 & 2.9 \\
\hline \multicolumn{3}{|l|}{ 3. Economic Rationality } \\
\hline 1. The farming activity and the environment create strong demand for irrigation water from the farmers & 76.3 & 3.9 \\
\hline $\begin{array}{l}\text { 2. Improved water management gives substantial increase in production and marketed surplus from the } \\
\text { farming activity }\end{array}$ & 53.5 & 3.3 \\
\hline 3. Improved water management leads to crop diversification and adoption of more profitable crops & 22.4 & 2.3 \\
\hline 4. Adequate infrastructure, marketing/processing arrangements are available to give good prices & 34.1 & 2.7 \\
\hline 5. Improved water availability and management lead to good profitability for the farmers & 55.9 & 3.2 \\
\hline \multicolumn{3}{|l|}{ 4. Social Rationality } \\
\hline $\begin{array}{l}\text { 7. People of all social groups have the opportunity to be members, participate, and be on executive } \\
\text { committees/hold posts }\end{array}$ & 61.8 & 3.3 \\
\hline
\end{tabular}


Table 7. Assessment of rationalities-percent response.

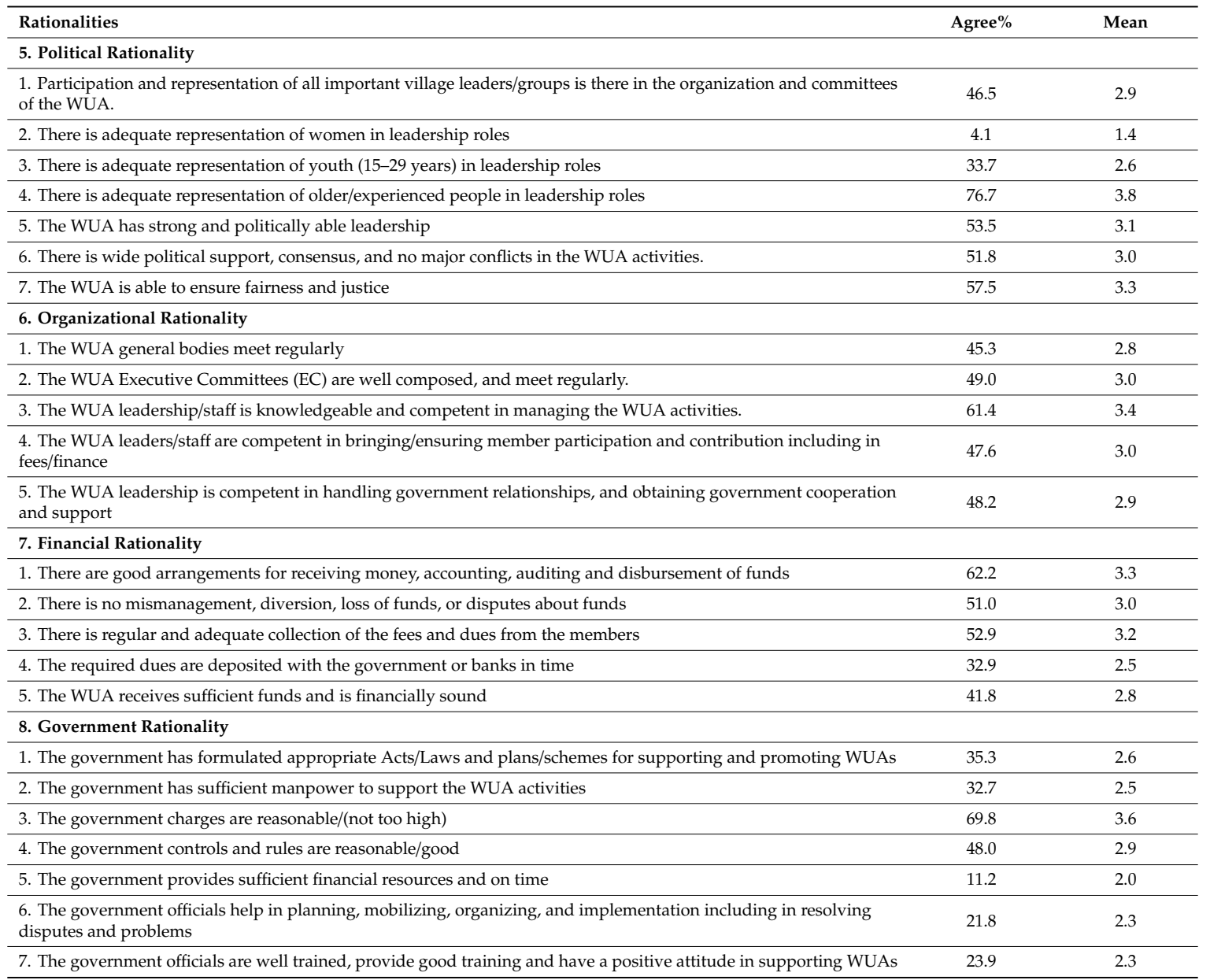

\section{Assessment of Institutional Features}

Relevant questions were also designed and asked regarding the status on different desirable institutional features-derived from new institutional economics fundamentals discussed above. About 5 to 7 pertinent questions were designed and asked to assess the status of each institutional feature on a Likert scale of 5 to 1 , strongly agree to strongly disagree. Table 8 provides the results of agree response (strongly agree plus agree) on each question, as well as the mean response.

On clear objectives, the objective and purpose of the institution are generally clear and are well communicated to everyone, but there is frequently no memorandum of understanding $(\mathrm{MoU}) /$ agreement with the government, and plans and actions to address the objectives are often inadequate, and often there are deviations. On good interaction, the interaction is generally quite good within the WUA but the number of meetings is inadequate, and the interaction with the government is low. On adaptiveness, the responses indicate that this is frequently inadequate and actual instances of adapting are not frequently seen. On scale and size, this is seen as too large by some, and too small by some, but the majority consider this to be reasonable. A large majority indicate that greater devolution to lower levels is required, and not greater centralization. Regarding compliance, a little over 50 percent indicate that there is compliance to the rules and schedules of water management and to the payment of dues, but the use of powers and penalties to bring compliance and reporting of non-compliance is inadequate. 
Table 8. Assessment on Institutional Features-Percent Response.

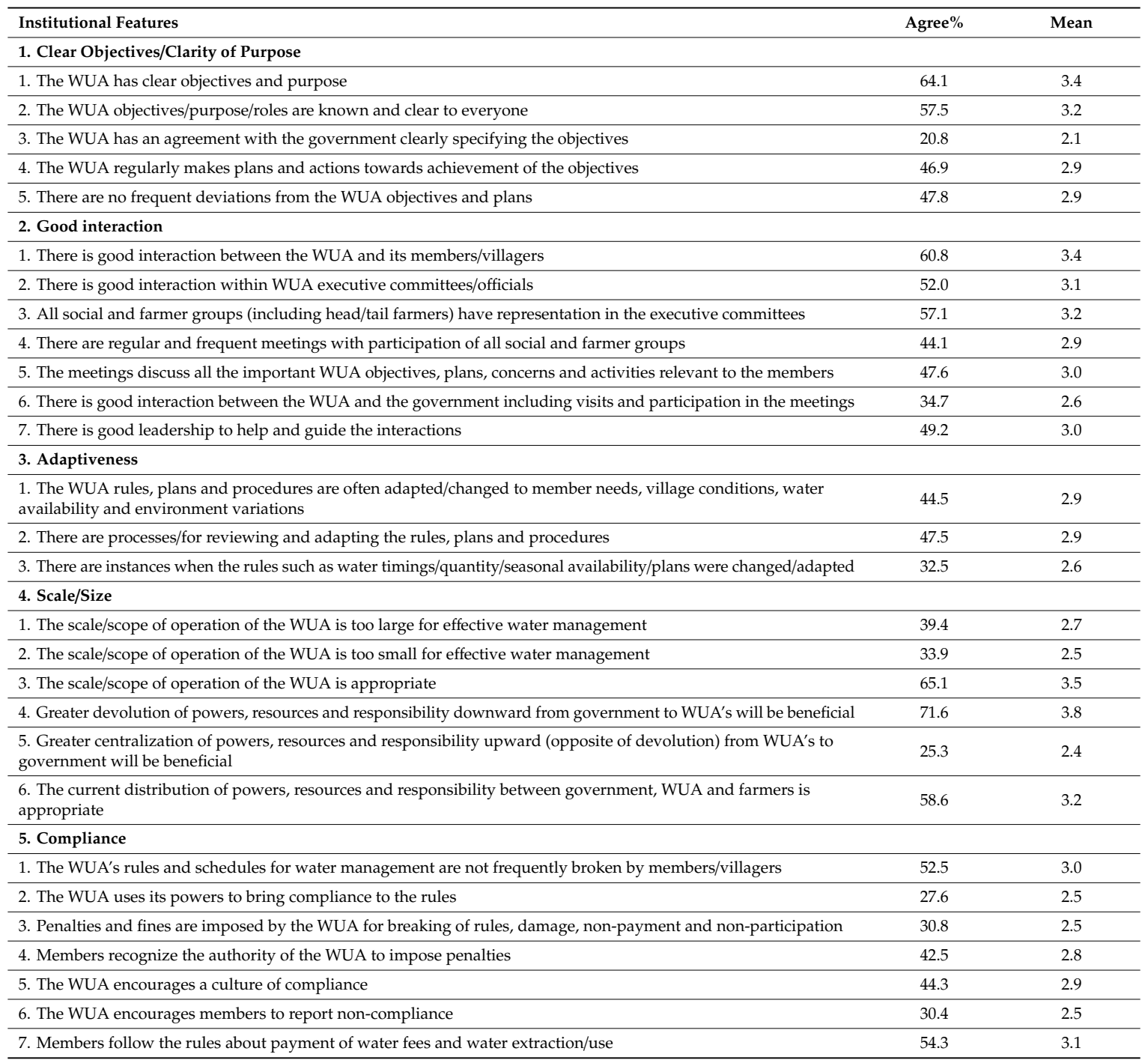

\section{Assessment of the Performance of the Water-User Associations}

In order to obtain an assessment of the performance of the WUAs from the point of view of the members/beneficiaries, questions on the performance were asked to them and summary of the responses are reported in Table 9. Results on overall performance show that about 40 percent have rated the performance of their WUA as good and only 6 percent have rated it as excellent. On the other hand, about 29 percent rate the performance as somewhat poor and 12 percent consider it as very poor. Views are also sought regarding the performance on different aspects including water availability, economic benefit, equity, environment and finance. The results in Table 9 indicate that there is considerable variation in the performance. Especially in water availability, equity and finance, many report poor performance.

Next, the study seeks to examine the relationship of the performance to the concepts and features of new institutional economics and management governance theory seen through the achievements on rationalities and institutional features discussed above. 
Table 9. Assessment of the performance of WUAs.

\begin{tabular}{|c|c|c|c|c|c|c|}
\hline Performance Aspects & $\begin{array}{l}\text { Excellent } \\
\quad \text { (5) }\end{array}$ & $\begin{array}{c}\text { Good } \\
(4)\end{array}$ & $\begin{array}{l}\text { Satisfactory } \\
\text { (3) }\end{array}$ & $\begin{array}{l}\text { Somewhat } \\
\text { Poor (2) }\end{array}$ & $\begin{array}{l}\text { Very Poor } \\
\text { (1) }\end{array}$ & Mean \\
\hline 1. Overall Assessment of the Performance of the WUA & 5.88 & 39.41 & 13.73 & 28.63 & 12.35 & 2.98 \\
\hline 2. Performance on Water Availability and Use & 2.16 & 29.61 & 27.84 & 29.41 & 10.98 & 2.83 \\
\hline $\begin{array}{l}\text { 4. Performance on Equity in Water Distribution and } \\
\text { Benefits }\end{array}$ & 2.55 & 32.75 & 26.86 & 29.22 & 8.63 & 2.91 \\
\hline 5. Performance on Environment Care and Impact & 0.78 & 39.22 & 33.14 & 20.59 & 6.27 & 3.08 \\
\hline 6. Performance on Financial Management & 2.75 & 18.82 & 28.63 & 35.69 & 14.12 & 2.60 \\
\hline
\end{tabular}

\subsection{Regression Analysis: Ordered Probit-Rationalities and Overall Performance}

To examine the relationship between the rationalities and performance in a multivariate framework, regression analysis is used. A composite of the six different performance indicators (with responses ranging from 5: Excellent to 1: very poor) is used to represent performance. Similarly, for each rationality, composites of the respective rationality assessment question responses (ranging 5: Strongly Agree to 1: Strongly Disagree) are used to represent each rationality. A state dummy is also included given that the data are from two different states (Assam and Bihar). Ordered probit is considered the appropriate econometric technique of analysis [30] given the nature of the performance indicator. The latent model is given as:

$$
\begin{gathered}
y^{*}=x^{\prime} \beta+\varepsilon \\
y=0 \text { if } y^{*} \leq 0 \\
=1 \text { if } 0<y^{*} \leq \mu_{1} \\
=2 \text { if } \mu_{1}<y^{*} \leq \mu_{2} \\
=3 \text { if } \mu_{2}<y^{*} \leq \mu_{3} \\
=4 \text { if } \mu_{3}<y^{*} \leq \mu_{4} \\
=5 \text { if } y^{*}>\mu_{4}
\end{gathered}
$$

The results for overall performance are given in Table 10. The results show statistically significant relationships between a number of the rationalities and performance. Technical rationality (TechR) shows a strong positive association indicating the importance of technical sound arrangements for performance. Economic rationality (EcoR) also shows a strong statistically significant relationship with performance indicating the need for attention to economic factors including crop-choice, productivity, prices and markets for performance. Besides this, social (SocR), environmental (EnvR), organizational (OrgR) and financial rationalities (FinR) also show positive and statistically significant associations with performance, indicating their relevance and importance. Political rationality (PolR) shows a slightly weaker but positive association, and government rationality has a negative coefficient. This may indicate difficulties in measuring this variables, as well as the need for optimal government involvement, not excessive. Overall, the results show the significant importance of a number of rationalities derived from the institutional management governance theory for performance.

\subsection{Regression Analysis: Ordered Probit-Institutional Features and Overall Performance}

The relationship between the institutional features and performance is also examined in a multivariate framework through the use of the appropriate econometric technique of ordered probit. As above, to represent performance, a composite of the six different performance indicators (responses ranging from 5: Excellent to 1: Very Poor) is used. Similarly, for each of the institutional features, composites of the respective institutional feature assessment question responses (5: Strongly Agree to 1: Strongly Disagree) are used to represent each of the institutional features. Besides, a state dummy is included given the data is from two different states (Assam and Bihar). The results for overall performance are given in Table 11. 
Table 10. Ordered probit regression results—rationalities and overall performance.

\begin{tabular}{ccccc}
\hline \multicolumn{5}{c}{ Parameter Estimates } \\
\hline Coefficient & Standard & & Approx \\
\hline Parameter & Estimate & Error & $\mathbf{t}$ Value & Pr $>|\mathbf{t}|$ \\
\hline Intercept & -3.481219 & 0.338816 & -10.27 & $<0.0001$ \\
TechR & 0.462224 & 0.100692 & 4.59 & $<0.0001$ \\
EnvR & 0.211463 & 0.099028 & 2.14 & 0.0327 \\
EcoR & 0.380315 & 0.079068 & 4.81 & $<0.0001$ \\
SocR & 0.430323 & 0.108434 & 3.97 & $<0.0001$ \\
PolR & 0.214952 & 0.116745 & 1.84 & 0.0656 \\
OrgR & 0.245714 & 0.081435 & 3.02 & 0.0026 \\
FinR & 0.188955 & 0.079932 & 2.36 & 0.0181 \\
GovR & -0.227159 & 0.082229 & -2.76 & 0.0057 \\
d1Bihar & -0.439755 & 0.128491 & -3.42 & 0.0006 \\
& Pseudo $R^{2}:$ Adjusted Estrella $=0.6065$, McKelvey-Zavinova $=0.6244$ & \\
\hline
\end{tabular}

Table 11. Ordered probit regression results—institutional features and overall performance.

\begin{tabular}{ccccc}
\hline \multicolumn{5}{c}{ Parameter Estimates } \\
\hline Coefficient & Standard & & Approx \\
\hline Parameter & Estimate & Error & $\mathbf{t}$ Value & Pr $>|\mathbf{t}|$ \\
\hline Intercept & -3.142061 & 0.384192 & -8.18 & $<0.0001$ \\
Clrob & 0.099127 & 0.072542 & 1.37 & 0.1718 \\
GooInt & 0.424164 & 0.08385 & 5.06 & $<0.0001$ \\
Adap & 0.270281 & 0.070108 & 3.86 & 0.0001 \\
ScSz & 0.675628 & 0.129632 & 5.21 & $<0.0001$ \\
Compl & 0.272105 & 0.09626 & 2.83 & 0.0047 \\
d1Bihar & 0.152624 & 0.122917 & 1.24 & 0.2144 \\
& Pseudo $R^{2}:$ Adjusted Estrella $=0.5865$, McKelvey-Zavinova $=0.6031$ & \\
\hline
\end{tabular}

The results indicate that all the institutional features have a positive relationship with performance and 4 out of 5 are statistically significant. Good interaction (GooInt) has a strong association indicating the substantial importance of representation, interaction and meetings. Scale/size (ScSz) also has a strong relationship with performance indicating the importance of the right choice in scale/size and the distribution/devolution of powers and responsibilities. Adaptiveness (Adap) has a significant relationship indicating the importance of keeping flexibility and avoiding rigidity in face of changes and variations. Compliance (Compl) too is significantly associated with performance indicating the importance of using WUA powers, penalties and other means to bring compliance to the institution's rules and schedules.

\subsection{Regression Analysis: Ordered Probit-Rationalities and Performance on Different Goals}

Apart from the relationship to overall performance, the relationship of rationalities to performance on different important performance goals is also examined on similar lines as above in a multivariate framework through ordered probit regression analysis. This includes performance on production/economic, equity, environment, and finance goals.

The results for production/economic performance are given in Table 12. The results indicate that the performance on production/economic goals is strongly related to technical rationality (TechR) and economic rationality (EcoR). It has a positive and statistically significant relationship also with organizational rationality (OrgR), government rationality (GovR) and political rationality (PolR). The results indicate that good outcomes on production/economic goals, therefore, require particular attention to these rationalities. 
Table 12. Ordered probit regression results—rationalities and production/economic performance.

\begin{tabular}{ccccc}
\hline \multicolumn{5}{c}{ Parameter Estimates } \\
\hline Coefficient & Standard & Approx & \\
\hline Parameter & Estimate & Error & $\mathbf{t}$ Value & Pr $>|\mathbf{t}|$ \\
\hline Intercept & -2.740752 & 0.360712 & -7.60 & $<0.0001$ \\
TechR & 0.383114 & 0.107075 & 3.58 & 0.0003 \\
EnvR & 0.105635 & 0.104989 & 1.01 & 0.3143 \\
EcoR & 0.705363 & 0.089667 & 7.87 & $<0.0001$ \\
SocR & 0.140418 & 0.116092 & 1.21 & 0.2265 \\
PolR & 0.274024 & 0.124089 & 2.21 & 0.0272 \\
OrgR & 0.260911 & 0.085511 & 3.05 & 0.0023 \\
FinR & 0.096296 & 0.084444 & 1.14 & 0.2541 \\
GovR & 0.195521 & 0.085208 & 2.29 & 0.0218 \\
d1Bihar & -0.804864 & 0.137402 & -5.86 & $<0.0001$ \\
& Pseudo $R^{2}:$ Adjusted Estrella $=0.6523$, McKelvey-Zavinova $=0.6777$ & \\
\hline
\end{tabular}

Another important goal of WUAs and PIM is improving equity of benefits and outcomes. The results for equity performance are given in Table 13. The results indicate that the performance on equity goals is strongly related to organizational rationality (OrgR) and political rationality (PolR). It has a positive and statistically significant relationship also with environmental rationality (EnvR) and economic rationality (EcoR). The importance of environmental rationality is perhaps because the poor/smaller farmers often farm on more environmentally fragile/poor lands and attention to environmental rationality benefits them more. Good outcomes on equity goals require attention to these rationalities.

Table 13. Ordered probit regression results—rationalities and equity performance.

\begin{tabular}{ccccc}
\hline \multicolumn{5}{c}{ Parameter Estimates } \\
\hline Coefficient & Standard & & Approx \\
\hline Parameter & Estimate & Error & $\mathbf{t}$ Value & Pr $>|\mathbf{t}|$ \\
\hline Intercept & -3.539881 & 0.347984 & -10.17 & $<0.0001$ \\
TechR & -0.079868 & 0.104015 & -0.77 & 0.4426 \\
EnvR & 0.371003 & 0.105366 & 3.52 & 0.0004 \\
EcoR & 0.216499 & 0.080782 & 2.68 & 0.0074 \\
SocR & 0.074102 & 0.112284 & 0.66 & 0.5093 \\
PolR & 0.530874 & 0.123912 & 4.28 & $<0.0001$ \\
OrgR & 0.522564 & 0.086478 & 6.04 & $<0.0001$ \\
FinR & 0.085388 & 0.083557 & 1.02 & 0.3068 \\
GovR & 0.11937 & 0.086023 & 1.39 & 0.1652 \\
d1Bihar & 0.21983 & 0.133267 & 1.65 & 0.099 \\
& Pseudo ${ }^{2}:$ Adjusted Estrella $=0.5666$, McKelvey-Zavinova $=0.6088$ & \\
\hline
\end{tabular}

Another important goal of WUAs and PIM is better environmental outcomes. The results for environmental performance are given in Table 14. The results indicate that the performance on environmental goals is strongly related to environmental rationality (EnvR) and economic rationality (EcoR). It is interesting that economic rationality also gives better environmental outcomes, perhaps through reducing the exploitation of more fragile natural resources for incomes. It has a positive and statistically significant relationship also with social rationality (SocR). The importance of social rationality is perhaps because the participation of various social groups is important for overall care of the environment. Good outcomes on environmental goals, therefore, require attention to these rationalities. 
Table 14. Ordered probit regression results—rationalities and environmental performance.

\begin{tabular}{ccccc}
\hline \multicolumn{5}{c}{ Parameter Estimates } \\
\hline Coefficient & Standard & & Approx \\
\hline Parameter & Estimate & Error & $\mathbf{t}$ Value & Pr $>|\mathbf{t}|$ \\
\hline Intercept & -1.811805 & 0.323559 & -5.60 & $<0.0001$ \\
TechR & 0.092052 & 0.098377 & 0.94 & 0.3494 \\
EnvR & 0.373877 & 0.098105 & 3.81 & 0.0001 \\
EcoR & 0.364374 & 0.078006 & 4.67 & $<0.0001$ \\
SocR & 0.27949 & 0.107367 & 2.60 & 0.0092 \\
PolR & 0.003186 & 0.115544 & 0.03 & 0.978 \\
OrgR & 0.065744 & 0.080312 & 0.82 & 0.413 \\
FinR & 0.054098 & 0.078984 & 0.68 & 0.4934 \\
GovR & 0.095183 & 0.078423 & 1.21 & 0.2249 \\
d1Bihar & 0.846352 & 0.127433 & 6.64 & $<0.0001$ \\
& Pseudo $R^{2}:$ Adjusted Estrella $=0.3251$, McKelvey-Zavinova $=0.3861$ & \\
\hline
\end{tabular}

\subsection{Ordered Probit-Financial Performance}

Financial strength of the WUA is also of considerable importance. The results for financial performance are given in Table 15. The results indicate that the performance on financial goals is strongly related to financial rationality (FinR) which may be expected, but it is also related to government rationality (GovR). The government being the major source of financial support, government rationality emerges of great importance. Good outcomes on financial goals therefore requires close attention to financial rationality but also to government rationality.

Table 15. Ordered probit regression results—rationalities and financial performance.

\begin{tabular}{ccccc}
\hline \multicolumn{5}{c}{ Parameter Estimates } \\
\hline Coefficient & Standard & & Approx \\
\hline Parameter & Estimate & Error & $\mathbf{t}$ Value & Pr $>|\mathbf{t}|$ \\
\hline Intercept & -1.864579 & 0.328574 & -5.67 & $<0.0001$ \\
TechR & 0.05084 & 0.101543 & 0.50 & 0.6166 \\
EnvR & 0.146444 & 0.099701 & 1.47 & 0.1419 \\
EcoR & 0.021094 & 0.079144 & 0.27 & 0.7898 \\
SocR & 0.054526 & 0.110431 & 0.49 & 0.6215 \\
PolR & -0.150727 & 0.118974 & -1.27 & 0.2052 \\
OrgR & 0.143716 & 0.08197 & 1.75 & 0.0796 \\
FinR & 0.526647 & 0.081936 & 6.43 & $<0.0001$ \\
GovR & 0.552462 & 0.082059 & 6.73 & $<0.0001$ \\
d1Bihar & -1.257892 & 0.133013 & -9.46 & $<0.0001$ \\
& Pseudo $R^{2}:$ Adjusted Estrella $=0.5575$, McKelvey-Zavinova $=0.5851$ & \\
\hline
\end{tabular}

\section{Conclusions}

India's Eastern Indo-Gangetic Plains have relatively abundant water but suffer from substantial institutional deficiencies in water management for agriculture which has negative consequences for development of the region. It has been shown that institutions and institutional design matter substantially and effective participatory institutions are very important for performance. Towards understanding the performance of water institutions in the region, the research has used concepts of new institutional economics and management governance theory to empirically study a sample of existing water institutions in the states of Assam and Bihar. A conceptual framework is developed which identifies a set of relevant rationalities and institutional features. Data from a sample of more than 500 farm households involved and across 51 institutions have been analyzed using univariate statistics and multivariate ordered probit regression analysis. The initial findings indicate significant 
inadequacies on a number of rationalities and institutional features in the institutions but considerable variation in them and the performance.

The relevance of different rationalities and institutional features in explaining performance variation is examined. The multivariate ordered probit analysis (based on a 5-point Likert scale) indicates that superior achievement on selected rationalities, particularly technical (e.g., structures and maintenance), economic (e.g., prices and profitability) and social (e.g., concern for small farmers, socially-backward and poor) are strongly and positively related to better overall performance with coefficients of $0.4622,0.3803,0.4303$, respectively. Other rationalities found positively and significantly related to performance are organizational (e.g., meetings and coordination), financial (e.g., financial control and strength) and environmental (e.g., resource conservation and drainage) with coefficients of $0.2457,0.1890,0.2115$, respectively. In the institutional features, good interaction (e.g., regular meetings and inclusive representation), adaptiveness (e.g., flexibility), and right scale (e.g., correct size and distribution of authority and responsibility), and compliance (e.g., following of rules) are positively and significantly related to performance with coefficients of $0.4242,0.2703,0.6756,0.2721$, respectively. Further analysis shows some variation by performance goals: for production/economic goals, technical, economic, and organizational rationalities are very important; and for equity goals, political, organizational, and environmental rationalities hold substantial significance. For environmental goals, environmental and economic rationalities are critical; and for financial goals, financial and government rationalities are important. A limitation of the study is the use of Likert-scales for obtaining responses on different aspects and the assumptions of the econometric techniques used. It is assumed and believed that these reflect the underlying reality. Besides, on several technical matters, since the data is scarce or not available, the performance measures used are perceived status or changes as seen by farmers. Another limitation is the given sample of institutions and beneficiaries covered which may or may not represent the population. The findings should be interpreted within the perspective of these limitations.

The results indicate the relevance and usefulness of the new institutional economics theory and management governance concepts in explaining the variation in institutional performance in the given context, and the efficacy of the conceptual framework for studying the performance. The results can provide guidance for government policy on design, development and reform of the water institutions as is urgently required in the region. For instance, the results show that the government or the PIM promoting agency should also have the capacity to address social, economic and environmental rationalities apart from technical rationality (which, as indicated, is often the only one addressed), to deliver strong performance in water management. In light of this, staff should be recruited from different educational backgrounds such as social work, agriculture, economics, environment and management in the water resources departments, and additionally, for the existing staff, reorientation training on these aspects should be given. Through this, efforts should be made to mainstream community engagement and participatory management of water. Attention is also required to see that there is good interaction in the WUAs through regular meetings, enhancing of adaptiveness in rules/systems, and having the right scale and devolution in the institutions, for achieving strong performance. The results show that just creating water institutions is important but not enough. The institutions need to be designed/structured, and given substantial guidance, training and support such that the different critical rationalities and institutional features are well addressed. This can go a long way in making participatory irrigation management in the Eastern Indo-Gangetic Plains stronger and more effective in delivering the required efficient water resource management.

Author Contributions: V.P.G.—conceptualization, research design, writing; and N.J.- field research, data analysis. All authors have read and agreed to the published version of the manuscript.

Funding: This research was funded by the Australian Centre for International Agricultural Research (ACIAR) project ADP2014/045. 
Acknowledgments: The authors would like to thank numerous researchers for their inputs, ACIAR for their support, state governments for their assistance, respondents for their time, and numerous workshop participants for their helpful comments.

Conflicts of Interest: The authors declare no conflict of interest.

\section{References}

1. Crase, L.; Gandhi, V.P. Reforming Institutions in Water Resource Management: Policy and Performance for Sustainable Development; Earthscan: London, UK, 2009; ISBN 978-1-138-86692-8.

2. Gandhi, V.P.; Namboodiri, N.V. Water Resource Development and Institutions in India: Overview and Profile. In Reforming Institutions in Water Resource Management: Policy and Performance for Sustainable Development; Crase, L., Gandhi, V.P., Eds.; Earthscan: London, UK, 2009; pp. 146-165.

3. Ostrom, E. Crafting Institutions for Self-Governing Irrigation Systems; ICS Press, Distributed to the Trade by National Book Network: San Francisco, CA, USA; Lanham, MD, USA, 1992; ISBN 978-1-55815-168-0.

4. Gandhi, V.P.; Namboodiri, N.V. Water Resource Management in India: Institutions and Development. In Proceedings of the International workshop held in Bangkok, Bangkok, Thailand, 8-9 June 2001; Brennan, D., Ed.; Australian Centre for International Agricultural Research (ACIAR): Canberra, Australia, 2002; pp. 106-130.

5. McCarthy, N.; Essam, T. Impact of Water User Associations on Agricultural Productivity in Chile; International Food Policy Research Institute (IFPRI): Washington, DC, USA, 2009.

6. Zhang, L.; Heerink, N.; Dries, L.; Shi, X. Water users associations and irrigation water productivity in northern China. Ecol. Econ. 2013, 95, 128-136. [CrossRef]

7. Wang, Y.; Wu, J. An Empirical Examination on the Role of Water User Associations for Irrigation Management in Rural China. Water Resour. Res. 2018, 54, 9791-9811. [CrossRef]

8. Verghese, B.G. Water Resources in the Northeast: Development Options in a Cooperative Framework; The World Bank: Washington, DC, USA, 2006; Available online: http://web.worldbank.org/archive/website01062/WEB/ IMAGES/PAPER_1_.PDF (accessed on 3 December 2019).

9. Mahanta, C. Water Resources in the Northeast: State of the Knowledge Base. 2006. Available online: http://siteresources.worldbank.org/INTSAREGTOPWATRES/Resources/Background_Paper_2.pdf (accessed on 3 December 2019).

10. Central Water Commission. Water \& Related Statistics (2015); Central Water Commission: New Delhi, India, 2018.

11. Bank, T.W. India-Development and Growth in Northeast. India: The Natural Resources, Water, and Environment Nexus; The World Bank: Washington, DC, USA, 2007; pp. 1-138.

12. UNICEF; FAO; SaciWATERs. Water in India: Situation and Prospects; UNICEF, India Country Office: New Delhi, India, 2013.

13. Douglass, N.C. Institutions, Institutional Change, and Economic Performance; Cambridge University Press: Cambridge, UK; New York, NY, USA, 1990; ISBN 978-0-521-39416-1.

14. Williamson, O.E. Economic Institutions and Development: A View from the Bottom. In A Not-So-Dismal Science; Olson, M., Kähköhnen, S., Eds.; Oxford University Press: Oxford, UK, 2007; pp. 92-118. ISBN 978-0-19-829490-0.

15. Olson, M.; Kähkönen, S. Introduction: The Broader View. In A Not-So-Dismal Science: A Broader View of Economies and Societies; Olson, M., Kähkönen, S., Eds.; Oxford University Press: Oxford, UK; New York, NY, USA, 2000; pp. 1-36. ISBN 978-0-19-829369-9.

16. Picciotto, R. Putting Institutional Economics to Work: From Participation to Governance; World Bank Discussion Papers; The World Bank: Washington, DC, USA, 1995; ISBN 978-0-8213-3458-4.

17. North, D.C. Prologue. In The Frontiers of the New Institutional Economics; Drobak, J.N., Nye, J.V.C., Eds.; Academic Press: San Diego, CA, USA, 1997; pp. 3-12. ISBN 978-0-12-222240-5.

18. Drobak, J.N.; Nye, J.V.C. (Eds.) The Frontiers of the New Institutional Economics; Academic Press: San Diego, CA, USA, 1997; ISBN 978-0-12-222240-5.

19. Crase, L.; Dollery, B.; Lockwood, M. Transaction Costs Emanating from Policy Flexibility in Water Markets. In Proceedings of the International Workshop Held in Bangkok, Bangkok, Thailand, 8-9 June 2001; Brennan, D., Ed.; Australian Centre for International Agricultural Research (ACIAR): Canberra, Australia, 2002; pp. 31-47. 
20. Curtis, A.; Robertson, A. Understanding landholder management of river frontages: The Goulburn Broken. Ecol. Manag. Restor. 2003, 4, 45-54. [CrossRef]

21. Saleth, R.M.; Dinar, A. The Institutional Economics of Water: A Cross-Country Analysis of Institutions and Performance; Edward Elgar: Cheltenham, UK, 2004; ISBN 978-0-8213-5656-2.

22. Pagan, P. Laws, Customs and Rules: Identifying the Characteristics of Successful Water Institutions. In Reforming Institutions in Water Resource Management; Crase, L., Gandhi, V.P., Eds.; Earthscan: London, UK, 2009.

23. Nystrom, P.C.; Starbuck, W.H. (Eds.) Handbook of Organizational Design: 1: Adapting Organizations to Their Environments; Oxford University Press: Oxford, UK; New York, NY, USA, 1981; ISBN 978-0-19-827241-0.

24. Groth, L. Future Organizational Design: The Scope for the IT-Based Enterprise; Wiley Series in Information Systems; John Wiley \& Sons: Chichester, UK; New York, NY, USA, 1999; ISBN 978-0-471-98893-9.

25. Ackroyd, S. The Organization of Business: Applying Organizational Theory to Contemporary Change; Oxford University Press: Oxford, UK; New York, NY, USA, 2002; ISBN 978-0-19-874269-2.

26. Gandhi, V.P.; Crase, L.; Herath, G. Comparing Indian Irrigation Institutions: What Determines Institutional Behaviour and Performance? Preliminary Empirical Observations. In Proceedings of the 2006 Conference (50th), Sydney, Australia, 8-10 February 2006; Australian Agricultural and Resource Economics Society: Canberra, Australia, 2006.

27. Gandhi, V.P.; Crase, L.; Roy, A. Water Institutions in the States of Andhra Pradesh, Gujarat and Maharashtra in India: An Empirical Study. In Reforming Institutions in Water Resource Management: Policy and Performance for Sustainable Development; Crase, L., Gandhi, V.P., Eds.; Earthscan: London, UK, 2009; pp. 20-44.

28. Gandhi, V.P. A Conceptual Framework for Studying Institutions in Watershed Development; Working Paper. No. 2010-11-04; Indian Institute of Management Ahmedabad: Ahmedabad, India, 2010; Available online: https://core.ac.uk/download/pdf/6443343.pdf (accessed on 2 September 2019).

29. Ministry of Agriculture \& Farmers Welfare. Agricultural Statistics at a Glance 2018; Ministry of Agriculture \& Farmers Welfare: New Delhi, India, 2018. Available online: https://eands.dacnet.nic.in/PDF/Agricultural\% 20Statistics\%20at\%20a\%20Glance\%202018.pdf (accessed on 10 July 2019).

30. Greene, W.H. Econometric Analysis; Pearson Education India: Delhi, India, 2003; ISBN 978-81-7758-684-8.

(C) 2019 by the authors. Licensee MDPI, Basel, Switzerland. This article is an open access article distributed under the terms and conditions of the Creative Commons Attribution (CC BY) license (http://creativecommons.org/licenses/by/4.0/). 